DOI: $10.20287 /$ doc.d24.ac05

\title{
O filme de busca e a construção ensaística de uma memória familiar emoldurada pelas montanhas mineiras
}

\author{
Adriano Medeiros da Rocha \& Eduardo Henrique Moreira*
}

\author{
Seu Carlito, narrativas sobre um comerciante da roça (Brasil, 2016, \\ 70min30seg) \\ Direção e Montagem: Eduardo Moreira \\ Produção: Eduardo Moreira e José Carlos Moreira \\ Fotografia e Som Direto: Eduardo Moreira e Thiago Novais \\ Trilha Sonara: Matheus Ferro
}

O início, o fim, e o meio...

A produção de um documentário envolve a captação de algum tipo matéria prima temática. Nesse processo, como também na edição, o cineasta expõe sua visão do tema abordado em seu filme, ele enquadra sua história. Na concepção de Sheila Bernard (2008), os filmes documentários se baseiam em fatos, e é disso que vem o seu poder e sua diferenciação do cinema de ficção. Partindo desse princípio, podemos entender os documentários como uma forma subjetiva de representação do mundo derivada das decisões do cineasta. Esses filmes são, portanto, carregados de sentidos próprios de quem os faz.

De acordo com Bill Nichols (2005: 47), os documentários não são uma reprodução da realidade, mas são representações do mundo que vivemos. Assim como fazem os outros meios de comunicação, no processo de produção de um documentário, os fatos são representados através da abordagem escolhida pelo diretor e sua equipe. Assim, essa abordagem emerge de uma série de escolhas.

Consuelo Lins e Cláudia Mesquita (2008: 58) consideram que a rede de escolhas que envolvem a produção documental é o "mais puro" artifício que gera o filme. Para os autores, os documentários "não brotam do coração do real, espontâneos, naturais, recheados de pessoas e situações autênticas", eles dependem da dedicação e envolvimento de seus realizadores

Sheila Curran Bernard (2008: 47) afirma que as redes de escolhas definem como as histórias são contadas nos documentários. Para ela, essa rede envolve

\footnotetext{
* Adriano Medeiros da Rocha: Universidade Federal de Ouro Preto, Instituto de Ciências Sociais Aplicadas, curso de Comunicação Social-Jornalismo. 35420000 - Mariana, Minas Gerais, Brasil. E-mail: adrianomedeiros.audiovisual@gmail.com Eduardo Henrique Moreira: Mestrando. Universidade Federal de Ouro Preto, Instituto de Ciências Sociais Aplicadas (ICSA), Programa de Pós-Graduaçao em Comunicação. 35420-000, Mariana, Minas Gerais, Brasil. E-mail: eduardomoreira.op@gmail.com
} 
escolhas criativas acerca da estrutura do filme, de perspectiva, de equilíbrio, de estilo, de elenco, entre outras. A autora entende que as escolhas caracterizam a abordagem do filme.

Dê a um grupo de cineastas alguma aparelhagem e a mesma história a ser contada em linhas gerais, e você acabará tendo em mãos filmes bastante diferentes em estilos, ponto de vista, enfoque e, na verdade, diversos em muito mais do que isso. Essas diferenças caracterizam a abordagem: como apresentar a história na tela. (Bernard, 2008: 47)

Cada filme documentário tem sua abordagem, ou seja, a rede de escolhas criativas feitas para sua realização. Portanto, como afirma Nichols (2005: 48), são todos diferentes, pois "não adotam um conjunto fixo de técnicas, não tratam apenas de um conjunto de questões, não apresentam apenas um conjunto de formas ou estilos". Bernard considera a maior parte dos documentários como sendo também narrativas e, em sua opinião, isso significa, pura e simplesmente, que eles contam histórias. Para a autora, a forma como estas obras contam as histórias e quais histórias contam são os elementos que separa esses filmes em subcategorias de gêneros ou estilo (Bernard, 2008:15).

Mesmo com as subcategorias que caracterizam alguma(s) abordagem(s), a prática está sujeita a constantes mudanças. Neste universo, há uma constante busca por abordagens alternativas e transformações no uso da linguagem. Refletindo sobre essa questão, Bernard ressalta que:

Ao discutir abordagem, tenha consciência de que os cineastas, conforme se mencionou, não raro combinam diferentes abordagens. Alguns usam narração (ou texto na tela, que desempenhe o mesmo papel), mas a usam com parcimônia. Outros combinam voice-over com narração, ou o roteiro com voice-over em lugar da narração. Alguns filmes fabricam situações que então se desdobram na tela, tornando-se, portanto, observacionais. (Bernard, 2008: 51)

Bill Nichols (2005) argumenta que os documentários representam questões, aspectos, características e problemas encontrados no mundo histórico por meio de sons e imagens que compões seus discursos, o que suscita a questão da $v o z$ que cada filme tem.

O fato de documentários não serem uma reprodução da realidade da a eles uma voz própria. Eles são uma reprodução do mundo, e essa representação significa uma visão singular do mundo. A voz do documentário é, portanto, o meio pelo qual esse ponto de vista ou essa perspectiva singular se dá a conhecer. (Nichols, 2005: 73)

Cada documentário tem sua voz fílmica, ou seja, uma natureza própria. Essa voz também pode ser entendida como uma impressão digital que atesta a individualidade do cineasta, ou até mesmo o poder de decisão de seus financia- 
dores. Sendo a maneira como o cineasta traduz seu ponto de vista e estabelece uma relação com mundo histórico, a voz fílmica remete ao estilo do filme. Para Bill Nichols (2005: 135), ao definir traços característicos semelhantes nas vozes individuais de filmes e cineastas, podemos estabelecer grupos que compartilham vozes semelhantes. Essas vozes compartilhadas referem-se aos gêneros de documentário.

Nichols divide os gêneros do documentário em seis modos: poético, expositivo, observativo, participativo, reflexivo e performático. Apesar de determinarem uma estrutura de afiliação frouxa, eles "estabelecem as convenções que um determinado filme pode adotar e propiciam expectativas específicas que os espectadores esperam ver satisfeitas" (Nichols, 2005: 135).

Por meio desta pesquisa, buscar-se-á investigar e compreender o tipo ou modo de documentário que Consuelo Lins e Cláudia Mesquita (2008: 55) consideram como ensaio fílmico, ou seja, aquele formato que remete a uma forma híbrida, sem regras nem definição exata, mas que articula modos de abordagem e composições variados, objetos e discursos heterogêneos. Para Bill Nichols (2005: 170) essas características mencionadas pelas autoras acima se aproximam ao modo que ele denomina performático. Este último teórico do cinema entende que filmes desse estilo dão mais ênfase às características subjetivas da experiência e da memória, se afastando do relato objetivo. Para ele, o significado é claramente um fenômeno subjetivo, carregado de afetos.

Um carro, um revólver, um hospital ou uma pessoa terão significados diferentes para pessoas diferentes. Experiência e memória, envolvimento emocional, questões de valor e crença, compromisso e princípio, tudo isso faz parte de nossa compreensão dos aspectos do mundo que mais são explorados pelo documentário (...). O Documentário performático sublinha a complexidade de nosso conhecimento do mundo ao enfatizar suas dimensões subjetivas e afetivas. (Nichols, 2005: 169)

Já Sílvio Da-Rin (2006: 183) aponta como elemento principal desse subgênero a auto-reflexidade, que constitui uma busca de alternativas às insuficiências e às limitações identificadas nos diversos modos de representação em lidar criticamente com o ilusionismo cinematográfico.

Os conceitos sobre este tipo de filme são variados e nem sempre conduzem a um consenso. Contudo, para esta pesquisa, adotaremos a perspectiva de que o ensaio fílmico possui sua hibridez justificada em suas variações demasiadas transições e transformações nas quais gêneros e estilos não se limitam, mas se complementam. A participação também acontece nesse tipo de filme, e é utilizada de diversas maneiras. Esses traços, segundo Nichols, são características que passam a aparecer nos documentários que ele denomina participativos. 
Quando assistimos a documentários participativos, esperamos testemunhar o mundo histórico da maneira pela qual ele é representado por alguém que nele se engaje ativamente, e não por alguém que observa discretamente, reconfigura poeticamente ou monta argumentativamente esse mundo. $\mathrm{O}$ cineasta despe o manto do comentário com voz-over, afasta-se da meditação poética, desce do lugar onde pousa a mosquinha na parede e torna-se um ator social (quase) como qualquer outro. (Nichols, 2005: 154)

Documentários participativos simulam o que é, para o cineasta, estar numa determinada situação e como ela consequentemente se altera. A experiência extraída do encontro entre o cineasta e o tema será o conteúdo do filme. O cineasta e tem a possibilidade de se posicionar como mentor, crítico, interrogador, colaborador ou provocador, ou mesmo como fio condutor da história. (Nichols, $2005: 155$ ).

Silvio Da-Rin (2006) acredita que, nesse modo ensaístico e interativo, “o cineasta dispõe de novos recursos para recusar o papel de agenciador oculto de imagens sonoras e visuais, podendo exibir-se como um ser humano implicado" (Da-Rin, 2006: 155 e 156). Além dessas características, Dan-Rin aponta também para o antiilusionismo que se manifestou de forma colateral no estilo interativo que permeia o filme ensaio.

No modo interativo, o antiilusionismo se manifesta de forma colateral, apesar da contribuição inaugural de ChroniquedùnÉté. Um dos fatores que marcou a novidade radical foi a liberdade com que os equipamentos de filmagem e os membros da equipe eram exibidos. (...) Fundava-se ali a tendência de deslocar o documentarista dos bastidores para a superfície do filme, substituindo a voz off incorpórea por um corpo humano visível que interage com os atores sociais. (Da-Rin, 2006: 183)

Conforme Nichols (2005: 158), há casos em que o cineasta se distancia da postura investigativa para adotar uma relação mais receptiva e reflexiva frente aos acontecimentos que o filme deseja contar ou que envolvem este profissional e seu tema. Essa escolha leva o filme a se aproximar do diário e do testemunho pessoal. Nesse tipo de narrativa é comum encontrarmos a voz na primeira pessoa predominando na estrutura global do filme. Seria o engajamento participativo do cineasta, agora também como sujeito registrado, um dos principais elos para se conseguir a atenção do público.

(...) é o desempenho de Emiko Omori na reconstituição da história reprimida da experiência de sua própria família, nos campos de confinamento de nipoamericanos durante a Segunda guerra Mundial, que dá forma a Coelho na lua (1999). Em Diário inconcluso (1983), Marilu Mallet propõe uma estrutura ainda mais explícita, na forma de diário, ao fazer o retrato de sua vida de exilada chilena em Montreal, casada com o cineasta canadense Michael Rubbo. (...) Esses filmes fazem do cineasta uma pernona tão nítida quanto 
qualquer outra de seus filmes. Como testemunho ou confissão, muitas vezes, estes manifestam um poder revelador. (Nichols, 2005: 158 e 159)

O crítico de cinema afirma que a intensidade emocional e a expressividade subjetiva do modo performático tomaram forma nos anos 80 e 90 e foram desenvolvidos principalmente por grupos que possuíam forte atenção para a esfera social e as questões comunitárias. De acordo com Cláudia Mesquita e Consuelo Lins (2008), essas características ensaísticas no Brasil são notáveis em filmes dos anos 80, como Mato eles? (1982), de Sergio Bianchi e Ilha das Flores (1989), de Jorge Furtado.

Os filmes desse estilo são carregados de emoção e significados que dão a eles características expressivas de uma dada perspectiva. Desse modo, os documentários performáticos dirigem aos espectadores uma representação pessoal e pontual de sujeitos específicos, incluindo o cineasta. (Nichols, 2005: 43). Dialogando com Nichols, Silvio Da-Rin entende que o cineasta assimila os recursos retóricos desenvolvidos ao longo da história do documentário e produz uma inflexão deles sobre si mesmos.

Não satisfeito em simplesmente expor argumentos sobre seu objeto, o cineasta passa a engajar-se em um metacomentário sobre os mecanismos que dão forma a este argumento. No lugar da ênfase absoluta sobre os personagens e os fatos do mundo histórico, o próprio filme afirma-se como fato no domínio da linguagem. (Da-Rin, 2006: 170)

Para Nichols, o estilo performático, ou o ensaio-fílmico, mistura livremente as técnicas expressivas que dão textura e densidade àquela ficção que ainda era presente nos modos poético e expositivo, mas que foi sendo deixada de lado quando o modo observacional priorizou a filmagem direta do encontro social, ou seja, possibilidades audiovisuais como planos de ponto de vista, números musicais, representações de estado subjetivo da mente, retrocessos, fotogramas congelados.

Nichols (2005: 171) ainda ressalta que os filmes desse estilo "nos envolvem menos com ordens ou imperativos retóricos do que com a sensação relacionada com sua nítida sensibilidade". Em sua opinião, a sensibilidade do cineasta busca estimular a do espectador, ou seja, é a carga afetiva aplicada no filme que indiretamente nos envolve na sua representação do mundo histórico.

Um dos métodos utilizados para a realização dos documentários de ensaio é o que o crítico cineasta Jean-Louis Comolli (2008) chama de dispositivos de escritura. Consuelo Lins e Cláudia Mesquita entendem que o dispositivo de escritura está relacionado à criação, pelo realizador, de um artifício ou protocolo produtor de situações a serem filmadas ou a um tipo de maquinação de uma lógica, de um pensamento, que atribui às condições, regras e/ou limites 
para que esses filmes aconteçam. Na opinião das autoras, a adoção de um dispositivo nega diretamente a ideia de documentário como obra que aprende a essência de uma temática ou realidade fixa e preexistente.

Não se trata, porém, de um procedimento produtor que gera efeitos semelhantes em todo o filme, mas que é criado a cada obra, imanente, contingente às circunstâncias de filmagem, e submetido às pressões do real. A simples adoção de um dispositivo não garante, em suma, o sucesso de um filme; tudo depende da sua adequação ao assunto eleito, mas sobretudo do trabalho concreto de filmagem, que a maquinação anterior não dispensa. (Lins \& Mesquita, 2008: 57)

O documentarista Eduardo Coutinho, ao refletir sobre dispositivo fílmico, utilizava o termo prisão para caracterizar o conjunto de regras auto impostas que delimitam o processo de realização de seus documentários. O dispositivo utilizado pelo cineasta, pelo menos até Edifício Master (2002), era de ordem espacial: filmar numa única locação (Lins e Mesquita, 2008). Porém, esse tipo de abordagem só foi evidenciado no decorrer dos anos 2000 pelos documentários Um passaporte húngaro (2002), de Sandra Kougut, e 33 (2003), de Kiko Goffman, os quais Consuelo Lins e Cláudia Mesquita denominam filmes de busca.

Neles, o motivo da realização do documentário deixa de ser a alteridades clássica para se relacionar a aspectos da experiência pessoal e da subjetividade dos próprios realizadores. Nos dois filmes, os diretores interagem com personagens e situações como sujeitos interessados, protagonistas de um processo de busca pessoal. (Lins \& Mesquita, 2008: 51)

Lins e Mesquita notam que as histórias registradas não preexistem à filmagem, mas são produzidas por um agir do documentarista, portanto, eles são também o fio condutor de seus filmes. Segundo Lins e Mesquita, o crítico Bernadet aposta no híbrido pessoa-personagem:

Como notou Jean Claude Bernadet: "O documentarista determina um projeto, sabe de onde parte, sabe o que gostaria de alcançar, mas não pode prever os resultados a que chegará nem o percurso que terá de cumprir. (...) Essas pessoas-personagens têm objetivos, enfrentam obstáculos, alcançam seus objetivos ou não, exatamente como nos filmes de ficção". (Lins \& Mesquita, 2008: 52)

A partir do diálogo teórico apresentado anteriormente, pode-se entender que os filmes de busca são documentários dos modos participativo e performático, ou então são filmes de ensaio, que possuem um dispositivo que faz o cineasta sair em busca de um objetivo. Nesse tipo de documentário, é estabelecida uma conexão entre o domínio privado e o domínio público, como acontece em Um passaporte húngaro (2002). Dessa forma, o cineasta faz sua representação do mundo histórico de maneira subjetiva através da exibição de 
uma busca íntima, marcando a diferença desse documentário em relação à exposição da vida privada a que se assiste diariamente na televisão.

Lins e Mesquita apontam também como traço marcante dos documentários de busca a utilização da entrevista com uso deslocado, sem reproduzir a tradicional dicotomia sujeito-objeto. Para elas, as entrevistas aparecem nos filmes de busca como "instrumento para obtenção de informações no processo concreto de pesquisa e busca empreendido pelos realizadores." (Lins \& Mesquita, 2008: 52).

Inspirados em conceitos encontrados nos filmes de busca e no mecanismo da pessoa-personagem, os realizadores Eduardo Moreira e Thiago Novais também decidiram ir a campo para desenvolver o primeiro média metragem da dupla, em 2016. O documentário, ou ensaio fílmico, que realizaram também pode ser identificado como um filme de busca. Um dos realizadores da obra - Eduardo Moreira - é o personagem condutor da história numa busca pela memória do seu avô, Carlos Moreira. O dispositivo escolhido para a gravação é a trajetória da equipe saindo da cidade de Ouro Preto com destino ao subdistrito de Piranga onde viveu Carlos, o Manja Léguas. Durante o percurso, a dupla passou pelos distritos ouropretanos: Santa Rita de Ouro Preto, Bandeiras e Santo Antônio. Nas várias paradas a dupla entrevistou filhos e netos do patriarca da família Moreira. Também nessas localidades foi feito o registro em vídeos das paisagens, situações cotidianas e objetos que representam a cultura e o estilo de vida da zona rural mineira. Da mesma maneira, foram registradas cenas do cotidiano dos entrevistados que remetem, ou representam, elos de relacionamento com Carlos Moreira. Segundo Bernard (2008: 185) é preciso haver imagens de cobertura suficientes para dar opções para a edição.

Pense em rodar o seu documentário como você faria com um drama: no âmbito de determinada cena você desejará tomadas amplas, tomadas médias, close-ups e cortes, para garantir que as tomadas sejam suficientemente longas e estáveis para serem usadas. Você quer ser capaz de criar cenas visuais que proporcionem contexto e alguma outra informação à história. (Bernard, 2008: 185)

O percurso regido pelo dispositivo adotado representa um mergulho feito pelo personagem central na história do avô de Eduardo. Através da vontade de resgatar parte significativa de uma memória de sua família, o neto de Carlos, que só o conheceu pelas histórias que ouvia do seu pai, dos tios e da falecida avó, decidiu embarcar em uma viagem para o Manja Léguas e documentar essa busca. A cada parada, um ou mais encontros com os tios e primos, que contaram e demonstraram, através das suas narrativas, quem foi Carlos dentro daquela memória coletiva. As interações tiveram um caráter mais íntimo/pessoal por se tratar de um encontro em família para compartilhar 
a memória da mesma. Esse tipo de encontro para conversas sobre temas familiares, normalmente, é uma situação rotineira no cotidiano dos habitantes da zona rural. A partir do conteúdo das entrevistas houve a tentativa de apresentar os aspectos imagéticos e também emocionais desses encontros.

Para que os entrevistados não se sentissem muito incomodados com a presença da(s) câmera(s) durante os diálogos, primeiramente a equipe buscou constituir um tempo de interação com cada um deles. Logo no momento da chegada ao ambiente de moradia ou trabalho de cada entrevistado o registro já começava a ser feito, a câmera era logo apresentada ao entrevistado e o equipamento registrador seguia o caminho. Na sequência, o entrevistado apresentava a sua casa/trabalho e, aos poucos, era estabelecida uma relação mais amena com a câmera. Após esse período de aproximação, a entrevista em profundidade era realizada.

Ao se aproximar e estabelecer um tempo de convívio com seus parentes do interior, o ator social central se aprofundou cada vez mais da história de sua família. A cada encontro era promovida também uma nova descoberta que remetia ao passado da família e atestava contestações de seu presente. $\mathrm{O}$ universo de expectativas e impressões geradas pelos encontros foi ilustrado pelas imagens de uma segunda câmera, que colocava o pesquisador, literalmente, como agente participativo. Esse registro foi tentado no calor do momento em cada uma das chegadas e partidas.

As experiências obtidas durante o trajeto pelas estradas repletas de paisagens diferenciadas e localidades típicas da zona rural mineira e também de cada um dos encontros com os familiares do personagem que buscava a história do seu avô foram registrados em duas perspectivas: em primeira pessoa, pelo próprio personagem e sua câmera, e em terceira pessoa por um companheiro de viagem - Thiago Novais. O objetivo foi ter um ponto de vista além do que era registrado pelo personagem central que fez a busca. Essas imagens de cobertura explicitam detalhes dos cenários, dos personagens e da natureza dos encontros, na tentativa de ilustrar o universo cultural e simbólico que os envolve. Conforme o entendimento de Bernard (2008: 185), é importante garantir as informações visuais necessárias para o registro da busca do personagem central, a personalidade dos entrevistados e os encontros.

Note que você está filmando casualmente tudo que for possível: está assegurando que possui informação visual passível de transmitir a informação narrativa básica: o que, onde, como. Quer estabelecer tempo, lugar e pessoas, buscando imagens que possam lhe fazer cortar informações verbais. Atente nos detalhes narrativos que revelam personagens: pode ser um cigarro esquecido enquanto queima ou a pilha de garrafas de licor no lixo reciclável. Busque tomadas que mostrem como as pessoas se comportam umas em relação às outras e com que habilidade manuseiam suas ferramentas de trabalho. 
Você pode querer humor. E conforme foi mencionado, precisa estar certo de ter uma série suficiente de ângulos, tomadas e cortes que possibilitarão ao editor condensar horas de material em um filme final que conte uma história coerente e visualmente satisfatória. (Bernard, 2008: 185)

A dupla partiu da hipótese de que a identidade de Carlos Moreira, presente na memória daqueles que o conheceram, é resultado dos seus feitos em vida. Histórias sobre o patriarca da família Moreira são contadas e recontadas há cerca de meio século. Na família do caixeiro viajante as lembranças da sua trajetória já são repassadas para a geração dos seus bisnetos. Nas comunidades e distritos próximos ao Manja Léguas, até mesmo os filhos e netos dos que conviveram com Carlos em vida reconhecem sua importância na história da região.

Inicialmente, a vontade da dupla foi entender como se dá a construção da identidade do indivíduo. Em seguida também houve a necessidade de compreender o funcionamento da memória coletiva das famílias e da identidade familiar. Como o filme dialoga sobre memórias de uma família do interior, questões ligadas à complexidade do ambiente e das relações sociais encontradas na zona rural mineira também permeiam a obra.

No caminho teórico que embasou a pesquisa, a dupla de realizadores utilizou alguns conceitos chave, tais como identidade e família. Com base em Anthony Giddens (1938), pode-se afirmar que as ações do indivíduo são observadas e compreendidas por ele próprio e que são sustentadas por suas convecções e estados emocionais. O meio que cerca o indivíduo, a época e sociedade em que vive, os atributos culturais que lhe são dados, tudo isso se relaciona diretamente com as referidas questões que relacionam sua existência. Esses fatores envolvem também o processo de construção de significados baseados nos conjuntos de atributos culturais inter-relacionados que levam a definição da(s) identidade(s) do indivíduo (Castells, 1942: 22). Nesse sentido, Manuel Castells afirma que para um determinado indivíduo, ou ainda um ator coletivo, pode haver identidades múltiplas. Porém essa pluralidade é apontada pelo autor como uma "[...] fonte de tensão e contradição tanto na auto-representação quanto na ação social" devido à confusão existente entre o que é a identidade "[...] e o que tradicionalmente os sociólogos têm chamado de papéis, e conjuntos de papéis". (Castells, 1942: 22).

Do ponto de vista sociológico, toda identidade é construída. As experiências adquiridas pelo indivíduo ao longo de sua vida são processadas pelas instituições sociais nas quais ele está inserido e assim sua identidade é estabelecida. Nessa linha de raciocínio, Castells lança a hipótese de que quem constrói as identidades são os determinantes do conteúdo simbólico das iden- 
tidades coletivas e seu significado para aqueles que com ela se identificam ou dela se excluem.

A construção de identidades vale-se da matéria prima fornecida pela história, geografia, biologia, instituições produtivas e reprodutivas, pela memória coletiva e por fantasias pessoais, pelos aparatos de poder e revelações de cunho religioso. Porém, todos esses materiais são processados pelos indivíduos, grupos sociais e sociedades, que reorganizam seu significado em função de tendências sociais e projetos culturais enraizados em sua estrutura social, bem como em sua visão de tempo/espaço. Havendo aqui a hipótese de que, em linhas gerais, quem constrói a identidade coletiva, e para quê essa identidade é construída, são em grande medida os determinantes do conteúdo simbólico dessa identidade, bem como de seu significado para aqueles que com ela se identificam ou dela se excluem. (Castells, 1942: 23)

Castells (1942: 26) considera que a construção da identidade do indivíduo consiste no seu projeto de vida. Nesse ponto, o indivíduo que assume um papel dentro da sociedade é apenas um sujeito. $\mathrm{O}$ autor entende que sujeitos não são indivíduos, mesmo considerando que são constituídos a partir de indivíduos. Quando o indivíduo tem um projeto de vida diferente "talvez com base em uma identidade oprimida, porém expandindo-se no sentido da transformação da sociedade como prolongamento desse projeto" ele atesta sua identidade (Castells, 1942: 26).

Em um recorte espacial mais micro, Ana Rojas Acosta e Maria Amália Faller Vitale (2008) sugerem que as famílias sejam abordadas como "algo que se define por uma história que se conta aos indivíduos, ao longo do tempo, desde que nascem, por palavras, gestos, atitudes ou silêncios, e que será por eles reproduzida e ressignificada [...]" (Acosta \& Vitale, 2008: 26 e 27). Cada família faz isso de maneira particular, dados os seus distintos lugares e momentos.

Ao construir a sua própria história, ou o seu próprio mito, a família expressa o significado e a explicação da realidade que viveu. Ela se utiliza dos elementos objetivos e subjetivos da cultura em que vivem seus indivíduos. A delimitação simbólica da família acontece por meio dos referenciais sociais e culturais da determinada época e sociedade. Sendo assim, para Acosta e Vitale, trabalhar com famílias requer a abertura para uma escuta, a fim de localizar os pontos de vulnerabilidade, e também os recursos disponíveis.

Pensar a família como uma realidade que se constitui pelo discurso sobre si própria, internalizado pelos sujeitos, é uma forma de buscar uma definição que não se antecipe à sua própria realidade, mas que nos permita pensar como ela se constrói, constrói sua noção de si, supondo evidentemente que isto se faz em cultura, dentro, portanto, dos parâmetros coletivos do tempo e do espaço em que vivemos, que ordenam as relações de parentesco (entre irmãos, entre pais e filhos, entre marido e mulher. (Acosta \& Vitale, 2008: 26 e 27) 
Considerando que o ser humano se constitui simbolicamente, ou seja, se constitui a partir dos elementos culturais, pode-se entender que não há realidade humana exterior à cultura. Dessa mesma forma, a construção simbólica da família é feita com a partir da sua memória coletiva. O discurso social que a define reflete nas diferentes famílias como um espelho. Cada família faz sua própria tradução desse discurso e o reflete com a sua imagem filtrada pela singularidade das experiências vividas.

Partindo da noção de que a identidade da família é definida pela sua própria história, é possível considerar que a memória coletiva familiar está muito atrelada ao papel dos avós. Esses atores sociais representam um elemento-chave nos processos de identificação e, portanto, na construção do sentido de pertencimento entre os membros de uma família. Acosta e Vitale (2008) afirmam que, quando se pesquisa ao menos três gerações de uma família, a figura dos avós revela bem essa dimensão. Através deles é possível recuperar a história familiar, social, atingindo várias gerações.

Tanto aqueles que conheceram os avós pessoalmente, como os que só os conheceram por fotografias e histórias, tem neles a representação de figuras presentes no imaginário. As inserções sociais, culturais e as relações de gênero definem a trajetória desses personagens. Recordamos deles através da posição que ocuparam na família relacionada ao nosso próprio lugar (Acosta \& Vitale, 2008). Porém essas posições podem ir se modificando ao longo da vida. Acosta e Vitale defendem que a herança simbólica transmitida pelos avós, entendida também como os seus legados geracionais, compõe nossa memória coletiva familiar. Afinal, eles contribuem ou contribuíram de diversas formas na vida cotidiana das suas famílias.

A importância dos avós para a família é inegável. Com base em Kaës (2001), as autoras Acosta e Vitale (2008) afirmam que "o pensamento psicanalítico tem tradicionalmente apontado o papel simbólico da figura dos avós vivos ou mortos - na função de assegurar aos netos uma identidade enraizada no tempo imemorial". Segundo elas, os avós proporcionam uma identidade genealógica para a família. Nesse caso, a criança está no centro das transmissões inconscientes dessa "vida psíquica" que transpassam as gerações. De acordo com Acosta e Vitale, eles são os personagens que se movimentam de acordo com as gerações, mas que permanecem em nossa memória "como figuras cristalizadas" em determinado momento do percurso. A herança simbólica que é transmitida por eles se mantém ao longo de nossas vidas pode ser recriada no processo de continuidade e descontinuidade dos bens simbólicos que recebemos. 
No filme Seu Carlito: narrativas sobre um comerciante da roça a dupla de realizadores promove a busca pela identidade de Carlos Moreira e acaba por encontrar elementos significativos para entender o processo de construção da identidade do indivíduo, mas também da memória coletiva da família e da própria comunidade, sobretudo ambientada na zona rural de Ouro Preto. Para explorar a trajetória de um personagem desse meio foi necessário ir atrás daqueles que ainda reproduzem as narrativas sobre ele. Como a identidade do indivíduo é moldada por suas ações em vida, é possível acessar as informações presentes na memória coletiva e resgatar os elementos que estruturam a identidade do personagem pesquisado.

As narrativas da época em que o comerciante viveu no Manja Léguas foram cuidadosamente mapeadas pelos realizadores. Cada um dos atores sociais apresentou fragmentos e versões das várias histórias sobre o avô de Eduardo. $\mathrm{O}$ realizador, e também personagem do filme, Eduardo Moreira, teve a oportunidade de imergir nos resquícios da realidade rural em que seu avô viveu e, através dos encontros e conversas com seus tios e primos mais velhos, consegui acessar e registrar as narrativas sobre seu avô. Em sua viagem para o Manja, passou pelos cenários onde aconteceu boa parte das histórias que ouviu. A experiência proporcionou ao realizador conhecer a trajetória do seu avô e as narrativas inspiradoras daqueles que ainda guardam suas lembranças. A cada encontro recebeu de seus familiares as lições, lembranças e memórias que o patriarca deixou como herança, traduzindo-a, cuidadosamente, neste filme documentário de buscas e virtudes.

\section{Referências bibliográficas}

Acosta, A. R. \& Vitale, M. A. F. (2008). Famílias: redes, laços e políticas públicas. 4 ed. São Paulo: Cortez/Instituto de Estudos Especiais/PUC-SP.

Bernard, S. C. (2008). Documentário: Técnicas para uma produção de alto impacto. Rio de Janeiro: Elsevier.

Castells, M. (2001). O Poder da Identidade: Paraísos comunais: Identidade e significado na sociedade em rede, vol. II. São Paulo: Paz e Terra.

Comerford, J. C. (2003). Como uma família: Sociabilidade, territórios de parentesco e sindicalismo rural. Rio de Janeiro. RelumeDumará.

Comolli, J.-L. (2008). Ver e poder: A inocência perdida - Cinema, Televisão, Ficção, documentário. Minas Gerais: Editora UFMG.

Da-Rin, S. (2004). Espelho Partido: Tradição e Transformação do Documentário. Rio de Janeiro: Azougue Editorial.

Giddens, A. (2002). Modernidade e identidade. Rio de Janeiro: Zahar. 
Lins, C. \& Mesquita, C. (2008). Filmar o Real: sobre documentário brasileiro contemporâneo. Rio de Janeiro: Jorge Zahar.

Nichols, B. (2005). Introdução ao documentário. São Paulo: Papirus. 